\title{
A EVOLUÇÃO DA UNIVERSIDADE NO CONTEXTO DO ENSINO A DISTÂNCIA E DAS TICS
}

\section{THE EVOLUTION OF THE UNIVERSITY IN THE CONTEXT OF DISTANCE EDUCATION AND ICT}

\author{
Nathan Peixoto Oliveira \\ Université de Bordeaux, França \\ nathanpeixot@yahoo.com.br \\ Jader Luís da Silveira \\ Universidade Federal de Minas Gerais, Brasil \\ luisjader2010@hotmail.com
}

Rômulo Henrique Gomes de Jesus Universidade Tecnológica Federal do Paraná, Brasil romulohenriquegomes@hotmail.com

Thales Volpe Rodrigues Universidade Tecnológica Federal do Paraná, Brasil thales.volpe@hotmail.com

RESUMO: a evolução das Tecnologias da Informação e Comunicação (TICs) trouxe para o contexto educacional novos recursos para contribuir com o processo de ensinoaprendizagem. Dessa forma, este trabalho possui como objetivo analisar o impacto das TICs aplicadas no Ensino a Distância (EaD) do Instituto Federal de Minas Gerais Campus Avançado Arcos. Para esse fim, buscou-se, por meio de um estudo descritivo, verificar o uso das TICs no ambiente do EaD, apontando como elas podem contribuir para a formação dos estudantes. Como principal resultado, foi verificado que a aplicação das TICs favorece o propósito da educação a distância como massificação do aprendizado, aumento do acesso e direito constitucional à educação pública de qualidade e inclusão social.

PALAVRAS-CHAVE: Ambiente virtual de aprendizagem. Ensino a distância. Ensino superior. Sala de aula virtual. Tecnologias da Informação e Comunicação.

\begin{abstract}
Information and Communication Technologies (ICT) brought new resources to the educational context to contribute to the teaching-learning process. Thus, this work aims at analyzing the impact of ICTs applied to the distance education at the Federal Institute of Minas Gerais - Campus Advanced Arcos. To this end, it was sought through a descriptive study to verify the use of ICT in the distance learning environment, pointing out how they can contribute to the development of students. As a main result, it was verified that the application of ICT favors the purpose of distance education as massification of learning, increasing the access and constitutional right to quality public education and social inclusion.
\end{abstract}

KEYWORDS: Virtual learning environment. Open and distance learning. University education. Virtual classroom. Information and Communication Technologies. 


\section{Introdução}

O ensino a distância, ou EaD, já era uma realidade da civilização muito antes da chegada da internet e das tecnologias da informação e comunicação (TICs). Sabe-se que essa modalidade de ensino teve como precursores as correspondências, a televisão, as fitas de vídeo e de áudio e, também, o telefone como recursos para propagar o ensino e a aprendizagem.

As TICs trouxeram para o ensino novos modos para se pensar e fazer a Educação. Por meio de ferramentas digitais, o ensino e a aprendizagem ganharam espaço virtual e digital que permitem aos envolvidos no processo um ensino que acompanhe essa nova realidade dos dias atuais.

Com as TICs, importantes mudanças se fizeram presentes no ensino superior, entre elas o uso de recursos tecnológicos digitais como forma de aproximar a sala de aula virtual da presencial, como os ambientes virtuais de aprendizagem (AVA), os blogs, as wikis e as redes sociais virtuais, por exemplo, além de chats e videoconferências e, assim, "Passa-se simultaneamente a conceber um novo formato para o processo de ensino-aprendizagem, aberto, centrado no aluno, interativo, participativo e flexível" (MATTAR, 2011, p. 6).

Ademais, o uso das TICs na Educação tem como objetivo contribuir com o processo de ensino-aprendizagem, tanto na elaboração do material didático quanto na interação e integração do aluno com o professor. Dessa forma, cabe ressaltar a formação continuada de professores. No Brasil, temos o Programa Nacional de Informática na Educação, Prolnfo, do Ministério da Educação, que oferta formação para professores com foco nas TICs como recurso para a prática pedagógica. Essa formação permite que professores que trabalham com o EaD aprendam a fazer uso das TICs como instrumentos potencializadores do seu ofício, levando em consideração o uso pedagógico apropriado delas, como menciona Kenski (2007, p. 103):

Professores bem formados conseguem ter segurança para administrar a diversidade de seus alunos e, junto com eles, aproveitar o progresso e as experiências de uns e garantir, ao mesmo tempo, o acesso e o uso criterioso das tecnologias pelos outros.

Tendo em vista a realidade do EaD na universidade brasileira e o uso das TICs, este artigo possui como objetivo analisar o impacto das TICs no ensino a distância do Instituto Federal de Minas Gerais - Campus Avançado Arcos. Para esse fim, esta pesquisa adota a metodologia de estudo descritivo, tendo como base os cursos do ensino a distância do Instituto Federal de Minas Gerais, no Campus Avançado Arcos. Além disso, busca apoio teórico em autores que abordam ambos os temas, EaD e TICs, como De Almeida (2002), Farias (2013), Pimentel (2006), Castro (2000), entre outros.

\section{0 ensino a distância}

O conceito de ensino a distância possui concordância com o contexto histórico, político, social e a constante evolução das tecnologias da informação e comunicação. A sua definição pode variar de autor para autor, entretanto todos se aproximam em 
aspectos como a distância física entre professor e aluno, a forma de estudo e a promoção da interação através do uso por meio de tecnologias da informação e comunicação. sendo:

A legislação brasileira apresenta a definição de EaD, em seu artigo ${ }^{\circ}$, como

Educação a Distância é uma forma de ensino que possibilita a auto-aprendizagem, com a mediação de recursos didáticos sistematicamente organizados, apresentados em diferentes suportes de informação, utilizados isoladamente ou combinados, e veiculados pelos diversos meios de comunicação (BRASIL, 1998, s.p.).

Em uma perspectiva histórica, os primeiros indícios da existência do ensino a distância surgiram na Grécia e, logo depois, em Roma através de correspondências que traziam informações científicas. Em 1728 nos EUA, o professor Cauleb Phillips passa a enviar lições para pessoas que moravam em Boston por correspondências. Na Suécia em 1833, surgem os primeiros indícios do ensino a distância, e, na Inglaterra, em 1840 (LOBO NETO, 1995).

A institucionalização do ensino a distância teve seu marco no século XIX, segundo Pimentel (2006, p. 17).

Após as décadas de 1960 e 1970, a educação a distância, embora mantendo os materiais escritos como base, passou a incorporar articulada e integradamente o áudio e o videocassete, as transmissões de rádio e televisão, o videotexto, o computador e, mais recentemente, a tecnologia de multimeios, que combina textos, sons, imagens, assim como mecanismos de geração de caminhos alternativos de aprendizagem (hipertextos, diferentes linguagens) e instrumentos para fixação de aprendizagem com feedback imediato (programas tutoriais informatizados) etc.

O avanço da educação e da tecnologia da informação e comunicação tem incentivado o ensino a distância, possibilitando o proveito da economia de escala e alcance de público mais amplo e diversificado (MORENO, 2017). Suas principais vantagens são: economia no custo de transporte, material publicado e espaço físico (PEREIRA; WEN; TAVARES, 2015).

O EaD já alcançou países em desenvolvimento e desenvolvidos, sendo frequente o surgimento de novos cursos direcionados para o treinamento profissional e ensino formal. A popularização da internet e massificação do seu acesso através de dispositivos como smartphones, tablets e computadores estimulam o aprendizado por meio da utilização de práticas do ensino a distância. Os principais exemplos de sistemas globais de EaD são Coursera, EDX, Udacity e Khan Academy (CIDRAL, 2018).

Usada inicialmente como recurso para suprir a deficiência educacional na qualificação profissional e aperfeiçoamento, com sua crescente utilização, a modalidade de ensino a distância passou a ser vista como uma alternativa que complementa parte do sistema regular de ensino (PIMENTEL, 2006). Borba (2016) afirma que termos como "cursos online" e "mobilidade" fazem parte da vida dos educadores e estão presentes no dia a dia de $45 \%$ da população mundial que tem acesso à internet.

As aplicações do ensino a distância se encontram em diversas áreas, abrangendo 
a educação primária, superior, corporativa e o treinamento para funcionários do setor público (PEREIRA; WEN; TAVARES, 2015).

Para consolidar e alcançar melhores resultados no ambiente do ensino a distância, é necessário avaliar de forma contínua o processo de aprendizagem, levando-se em conta aspectos como: nível de interação dos autores envolvidos, efetividade das ações pedagógicas, iniciativas do aluno, utilização de recursos multimídia, dentre outros aspectos (RODRIGUES, 2018). período:

Cidral (2018) apresenta, no Quadro 1, as seguintes características do EaD por

Quadro 1: Características do EaD por período.

\begin{tabular}{|c|l|}
\hline De 2001 a 2003 & Focam o conteúdo do curso e a possibilidade de customização. \\
\hline De 2004 a 2006 & Focam a usabilidade das plataformas de ensino. \\
\hline De 2007 a 2009 & $\begin{array}{l}\text { Focam o nível de satisfação dos estudantes e metodologias de ensino a } \\
\text { distância. }\end{array}$ \\
\hline De 2010 a 2012 & Focam a satisfação e expectativa dos alunos do ensino a distância. \\
\hline A partir de 2013 & $\begin{array}{l}\text { Os estudos publicados possuem como foco o sucesso global do ensino a } \\
\text { distância e também como as características dos estudantes afetam o } \\
\text { ambiente de aprendizagem a distância. }\end{array}$ \\
\hline
\end{tabular}

Fonte: adaptado de Cidral (2018).

A temática do ensino a distância ainda tem sido bastante estudada, pois é uma alternativa decisiva para a massificação da educação de qualidade a baixos custos em um ambiente de aprendizagem flexível e que demanda profissionais com cada vez mais qualidades cognitivas. Embora ainda existam obstáculos para a difusão da tecnologia, o ensino a distância é uma tendência para as próximas gerações.

\subsection{O ensino a distância na universidade brasileira}

Segundo Alves (2011), as primeiras experiências em EaD no Brasil, provavelmente, ficaram sem registro, pois os primeiros dados conhecidos são do século XX. Foi nesse momento que o ensino a distância foi disseminado pelo avanço da tecnologia, nos meios de comunicação, permitindo ao Brasil ampliar, a partir da década de 70, sua história nessa modalidade por meio de programas de teleducação (SARAIVA, 2008).

No Brasil, em 1904, surge a primeira iniciativa para o ensino a distância, pela modalidade de ensino por correspondência, quando instituições privadas ofereciam cursos de iniciação profissional em áreas técnicas, sem necessidade de estudos anteriores. $O$ modelo foi consagrado na metade do século XX quando da criação do Instituto Monitor (1939), Instituto Universal Brasileiro e outras instituições que atenderam mais de três milhões de alunos através do ensino por correspondência (PIMENTEL, 2006).

Os projetos que contribuíram, no Brasil, para a disseminação da educação na modalidade a distância estão listados no Quadro 2: 
Quadro 2: Evolução do EaD no Brasil.

\begin{tabular}{|c|c|}
\hline 1904 & $\begin{array}{l}\text { Escolas internacionais, que eram instituições privadas, ofereciam cursos pagos, por } \\
\text { correspondência. }\end{array}$ \\
\hline 1934 & $\begin{array}{l}\text { Edgard Roquete-Pinto instalou a Rádio-Escola Municipal no Rio. Estudantes tinham } \\
\text { acesso prévio a folhetos e esquemas de aulas. Utilizava também correspondência } \\
\text { para contato com estudantes. }\end{array}$ \\
\hline 1939 & Surgiu o Instituto Universal Brasileiro, em São Paulo. \\
\hline 1941 & Primeira Universidade do Ar, que durou dois anos. \\
\hline 1947 & Nova Universidade do Ar, patrocinada pelo SENAC, SESC e emissoras associadas. \\
\hline $1961 / 65$ & $\begin{array}{l}\text { Movimento de Educação de Base (MEB) - Igreja Católica e Governo Federal } \\
\text { utilizavam um sistema rádio-educativo: educação, conscientização, politizaçãa, } \\
\text { educação sindicalista etc. }\end{array}$ \\
\hline 1970 & $\begin{array}{l}\text { Projeto Minerva - convênio entre Fundação Padre Landell de Moura e Fundação } \\
\text { Padre Anchieta para produção de textos e programas. }\end{array}$ \\
\hline 1972 & $\begin{array}{l}\text { O Governo Federal enviou à Inglaterra um grupo de educadores, tendo à frente o } \\
\text { conselheiro Newton Sucupira: o relatório final marcou uma posição reacionária às } \\
\text { mudanças no sistema educacional brasileiro, colocando um grande obstáculo à } \\
\text { implantação da Universidade Aberta e a Distância no Brasil. }\end{array}$ \\
\hline Década de 70 & $\begin{array}{l}\text { Fundação Roberto Marinho - programa de educação supletiva a distância, para } 1^{\circ} \mathrm{e} \\
2^{\circ} \text { graus. }\end{array}$ \\
\hline 1992 & $\begin{array}{l}\text { Foi criada a Universidade Aberta de Brasília (Lei 403/92), podendo atingir três campos } \\
\text { distintos. }\end{array}$ \\
\hline
\end{tabular}

Fonte: Adaptado de Pimentel (2006).

Ainda segundo Pimentel (2006), nas décadas de 1970 e 1980, fundações privadas e organizações não governamentais iniciaram a oferta de cursos supletivos a distância através da teleducação. Sendo a década de 1990 o período em que a maior parte das intuições de ensino superior se mobilizaram para o ensino a distância.

Em 1994, é iniciada a expansão da internet no ambiente universitário e, em 1996, houve a reforma da educação brasileira pela Lei 9.394/96, que legisla sobre a política nacional e era normativa do ensino a distância no Brasil. Em fevereiro de 1998, através dos Decretos 2.494 e 2.561, são externados os procedimentos que deveriam ser adotados pelas instituições para credenciamento ao MEC para oferta de curso de graduação a distância (PIMENTEL, 2006).

Em abril de 2001, através da edição da Resolução 01, são fixados limites e exigências para o reconhecimento de cursos a distância ministrados por instituições estrangeiras. E através da portaria 2.253 é legislado sobre a oferta de disciplinas não presenciais, em seu todo ou em parte, para cursos reconhecidos pelo MEC, restringindo a carga horária da prática de ensino a distância a $20 \%$ da carga horária total do curso (PIMENTEL, 2006).

Em agosto de 2002, os Decretos 2.494 e 2.561 são revogados através da recomendação da Comissão Assessora para Educação Superior, decidindo-se por uma nova regulamentação. Entre as necessidades de mudanças estavam aspectos como a revisão do método adotado pelo MEC para reconhecimento de cursos a distância, a criação de padrões nacionais de qualidade etc. (PIMENTEL, 2006). 


\subsection{As TICs nas universidades brasileiras}

Discussões relacionadas ao EaD no ensino superior eventualmente abordam suas possibilidades e limites de uso. Dessa maneira, é importante retomar algumas dessas discussões associadas ao uso das TICs no desenvolvimento de conhecimento. Esse domínio, apesar de pouco investigado pelas instituições educacionais, é confundido como "espaço" exclusivo do ensino a distância (ALONSO, 2010).

Segundo Gomes (2009), o EaD é composto pela tríade discente, docente e conteúdo. A sinergia entre os elementos é garantida pela tecnologia. Dentre as principais formas de $\mathrm{EaD}$, tem-se a mídia impressa, a mídia sob forma de áudio e vídeo (como CDs e DVDs), o rádio e a televisão. Diversos recursos tecnológicos possibilitam a comunicação no sistema EaD, porém, com o advento da internet, tem-se novas ferramentas de telecomunicação interativa, como áudio, audiografia, audioconferências, vídeos, videoconferências e programas de computador autogerenciáveis pelo aluno.

As TICs podem ser consideradas a união dos recursos tecnológicos que proporcionam maior facilidade no acesso e na disseminação de informações. Essas tecnologias estão presentes no dia a dia da sociedade atual, em formas diversas, portanto uma das áreas mais beneficiadas pelo uso das TICs é o setor educacional (FARIAS, 2013).

Segundo Lévy (1998, p. 24):

Poucas inovações tecnológicas provocaram tantas mudanças em tão pouco tempo na sociedade como as novas tecnologias de informação e comunicação -TICs. Dentro dessas mudanças está incluída a educação. Novas maneiras de pensar e conviver estão sendo elaboradas no mundo das telecomunicações e da informática.

As TICs são adotadas com o propósito de colaborar com o processo de aprendizagem, seja na construção do material pedagógico ou para incitar a colaboração e interação entre os membros de determinado curso, facilitando, assim, o desenvolvimento coletivo de conhecimento (GOMES, 2016). A utilização das ferramentas tecnológicas no processo de aprendizagem é importante para incorporar os recursos didáticos, auxiliando na inclusão digital, além de permitir o compartilhamento de informações e experiências entre os discentes. Castells (2000, p. 57) ressalta que "as novas tecnologias de informação integram o mundo em redes globais de instrumentalidade. A comunicação mediada por computadores gera uma gama de comunidades virtuais".

Para Almeida (2003), propiciar o acesso às TICs para os alunos e posicioná-los diante das informações, problemas e objetos de conhecimento pode ser insuficiente para aproximá-los do processo de aprendizagem colaborativo. Nesse sentido, "É preciso criar um ambiente que favoreça a aprendizagem significativa ao aluno" (ALMEIDA, 2003, p. 79). Almeida (2002) descreve ambientes virtuais colaborativos como sistemas computacionais que auxiliam na exposição das informações de maneira organizada e no tempo apropriado.

As interações virtuais, constituídas por um grupo de pessoas que utilizam softwares específicos para a comunicação a distância, são mediadas pelas TICs. Dessa maneira, as TICs representam a interação essencial para o EaD, sendo que, em sua ausência, não há a possibilidade de interação entre aluno e professor (BARBOSA, 2012; 
MENDONÇA et al., 2012).

As inovações nos processos de desenvolvimento do conhecimento passam, indispensavelmente, pela utilização das TICs. Mas qual a razão do uso das tecnologias de suporte, instrumento ou material de apoio, se o método estiver com as bases teóricas comprometidas? Castro (2000, p. 32) evidencia que a solução seria uma rápida e eficiente capacidade de adaptação das instituições:

\begin{abstract}
Mudanças que se produzem em escala global estão obrigando os países a adequarem suas instituições e seus modos de funcionamento aos novos cenários que se configuram. [...] A universidade está diante de uma encruzilhada. Ou se desenvolve como uma instituição com valor para a sociedade, por sua tarefa de produção e reflexão acerca do conhecimento, ou se resigna a ficar como está. A última condição significaria morrer pouco a pouco.
\end{abstract}

Diversos autores corroboram a necessidade de realizar um aprofundamento sobre os aspectos pedagógicos, o uso das TICs e as diretrizes políticas necessárias para viabilizar a modalidade EaD como um instrumento poderoso de democratização do conhecimento, dentro dos padrões de qualidade exigidos pela academia. É inegável que o EaD possui potencial significativo para a inclusão de parte da população educacional do Brasil (PIMENTEL, 2006).

O estabelecimento de ações para o alcance nacional de planejamento e de aplicação de programas de integração das TICs, seja EaD ou na educação presencial, é, principalmente, uma responsabilidade de setores do governo. O papel das instituições seria, pois, concentrar-se na troca de experiências e firmar parcerias para superar a falta de investimentos financeiros e humanos, na busca por uma educação de qualidade em nível geral (MARTINEZ, 2017).

Infelizmente, o acesso às TICs ainda é uma dificuldade na realidade brasileira por uma parcela considerável da população, assim o EaD no Brasil prossegue coexistindo em diferentes comunidades. Porém, os cursos EaD podem se tornar mais interativos e assumir uma abordagem mais próxima do estar junto virtual a partir do envolvimento dos formadores em programas para sua própria formação continuada por meio das TICs que os levem a refletir sobre as contribuições dessas tecnologias à prática pedagógica. (PIMENTEL, 2006).

Entretanto, mesmo com as dificuldades encontradas para a adoção de TICs e com acesso limitado aos recursos tecnológicos, a oferta de cursos superiores no EaD brasileiro tem apresentado um crescimento significativo, assim como o uso das TICs, como mostra a Figura 1. 
Figura 1: Evolução do EaD brasileiro, devido ao uso de TICs.

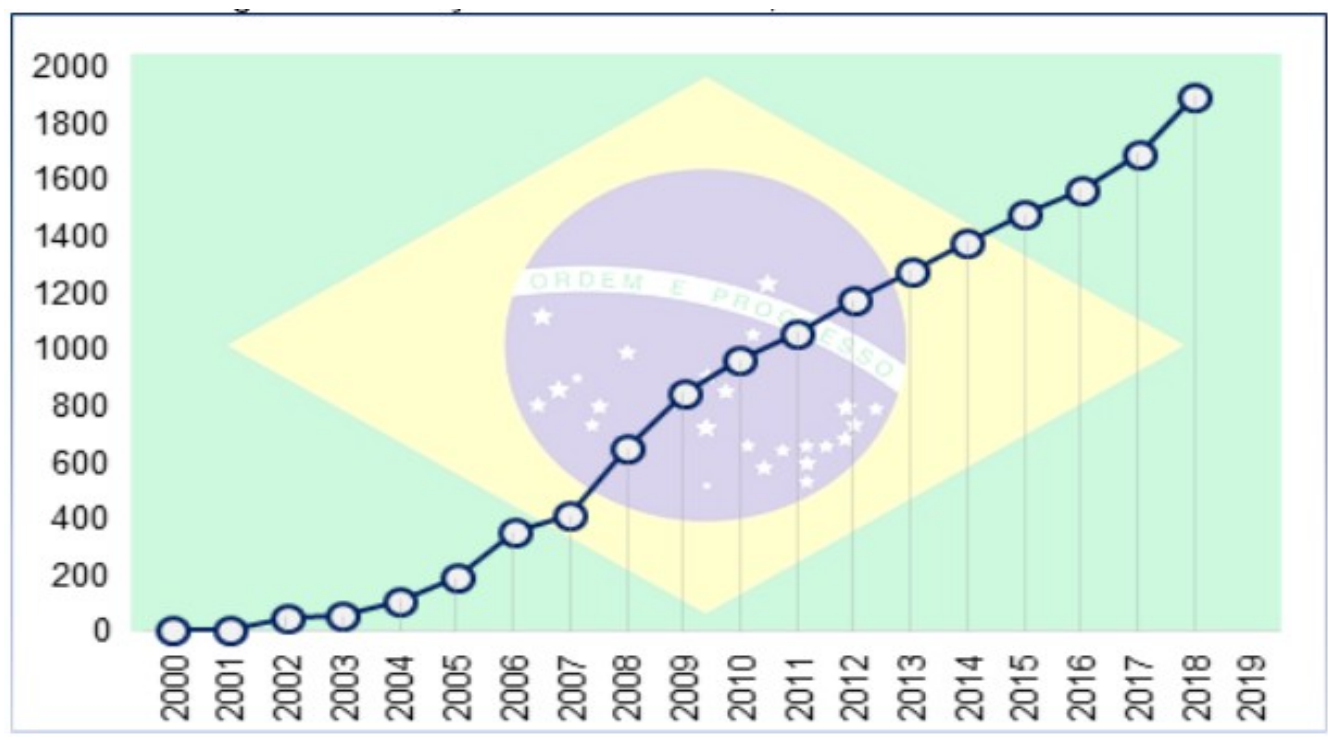

Fonte: Adaptado de MEC (2018).

Não se pode ignorar as possibilidades do EaD para a inclusão educacional de parcela considerável da população brasileira. Assim, conforme salientado pelo ForGRAD (2002), os desafios desta modalidade de ensino são congruentes com os desafios do sistema educacional em sua totalidade.

\section{O caso do EaD no IFMG}

O presente trabalho apresenta um estudo descritivo baseado nos cursos de ensino a distância do Instituto Federal de Minas Gerais, no Campus Avançado Arcos.

Segundo o Plano de Desenvolvimento Institucional (IFMG, 2014), o Instituto Federal de Educação, Ciência e Tecnologia de Minas Gerais (IFMG) é uma instituição pública de ensino, integrante da Rede Federal de Educação Profissional e Tecnológica do Ministério da Educação, que oferta, principalmente, cursos técnicos e superiores e possui uma Reitoria (unidade administrativa) em Belo Horizonte, além de campi em 17 cidades.

Busca-se, através do ensino a distância (EaD), a expansão do ensino técnico e superior. O EaD do IFMG está organizado em quatro estruturas que apoiam a gestão do $\mathrm{EaD}$ junto à Diretoria de Desenvolvimento Institucional (DDI). A Coordenação Geral de Educação a Distância (CGEAD) é o órgão responsável pela Política Institucional de Educação a Distância; o Comitê Permanente de Assessoramento em Educação a Distância (COPEAD) é responsável pelo desenvolvimento de políticas de EaD no âmbito da instituição. Já o NEAD - Núcleo de Educação a Distância é o núcleo gestor responsável pela execução das políticas de $\mathrm{EaD}$, que, vinculado à CGEAD, atua no oferecimento de apoio técnico operacional nas áreas administrativa, pedagógica e tecnológica aos campi, na implantação e desenvolvimento de projetos, cursos, programas da modalidade. Por fim, a Divisão de Apoio aos Programas é uma estrutura independente responsável pela gestão, planejamento e acompanhamento dos programas governamentais de Educação a Distância, no âmbito do IFMG (IFMG, 2014). 
Tendo em vista ampliar ainda mais o processo de democratização da educação profissional e tecnológica, o IFMG, por meio de seu Centro de Educação a Distância (CEAD), tem se apoiado em inovadoras TICs para prover educação a distância (IFMG, 2019).

O IFMG Campus Avançado Arcos implantou no ano de 2018 o seu Comitê de Educação a Distância com a função de receber a então recém-inaugurada PósGraduação Lato Sensu em Docência com ênfase na Educação Básica. Esse Campus foi o segundo da rede a implantar o ensino a distância, ficando atrás apenas do Campus Ouro Preto, que foi o pioneiro.

O CEAD é um órgão criado a fim de fornecer suporte aos cursos a distância em suas necessidades operacionais, auxiliando o processo de ensino-aprendizagem mediado por tecnologias (IFMG, 2019).

A adoção do Moodle como ambiente virtual de aprendizagem (AVA) tem-se mostrado uma iniciativa bastante promissora, em que, inicialmente, a função era abrigar as disciplinas da especialização em Docência. Hoje, o AVA abriga, além das disciplinas da especialização, outros cursos como os de formação inicial e continuada (FIC), disciplinas a distância do curso técnico e de graduação da modalidade presencial (Figura 2).

Figura 2: Interface da Página Inicial do Moodle.

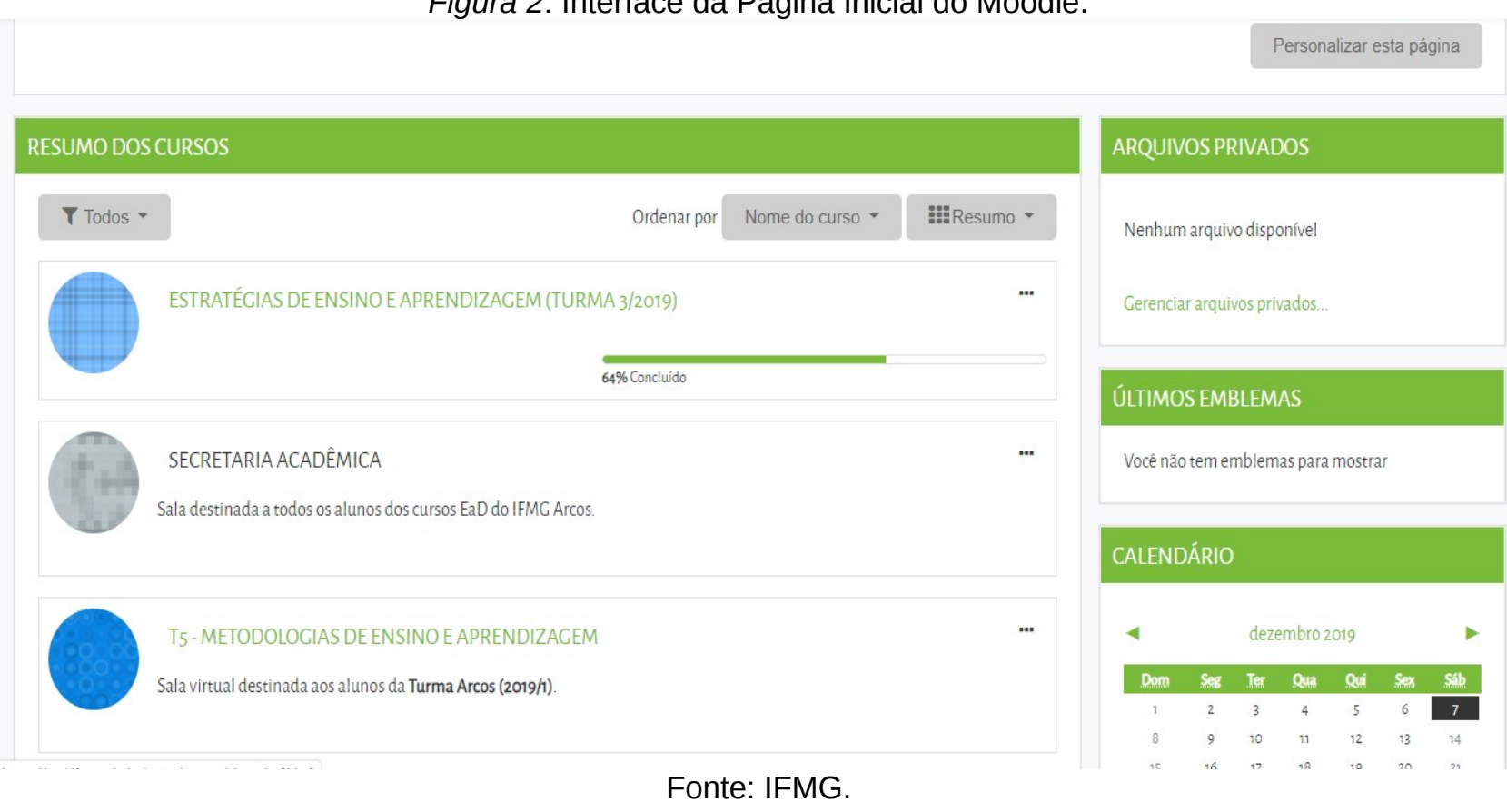

A utilização do AVA Moodle como estratégia de ensino-aprendizagem fez com que o corpo discente aumentasse em mais de $800 \%$ quando comparado à época em que 0 Campus tinha apenas alunos na modalidade presencial. Segundo o site da Instituição, os números do curso de Formação Continuada Estratégias de Ensino e Aprendizagem impressionaram a todos, com 1400 alunos matriculados, um número acima do esperado em sua primeira oferta de cursos EaD (IFMG, 2018). Um exemplo do AVA para um curso de formação continuada em tecnologias na educação é mostrado na Figura 3, a seguir. 
Figura 3: Página de um curso oferecido pela Instituição.

\section{TECNOLOGIAS NA EDUCAÇÃO}

Curso de Formação Continuada

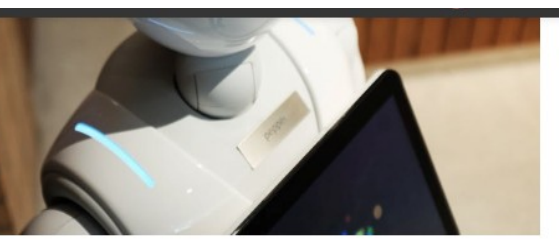

Professor: Niltom Vieira (niltom.vieira@ifmg.edu.br)

Professor: ]efferson Silva (jefferson.silva@ifmg.edu.br)

Tutor responsável: Jader Silveira (luisjader2010@hotmail.com)

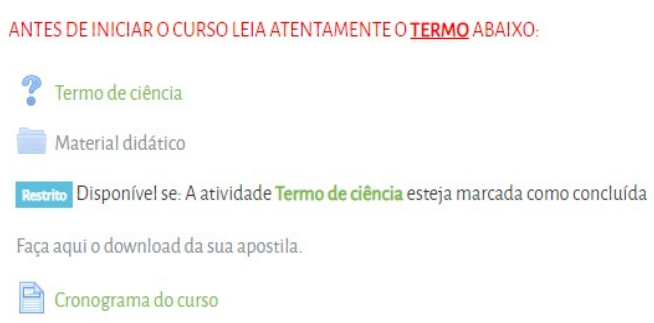

ATENÇÃO: CONFIRA SEU NOME ANTES DE EMITIR O SEU CERTIFICADO!

Fonte: IFMG.

Segundo um dos discentes que preferiu não ser identificado, constatou-se que a instituição promove a democratização do ensino com os seus cursos e uso do AVA: "Atuo há poucos meses na rede municipal de Cariacica-ES e a oportunidade de fazer o curso totalmente a distância possibilita que professores de todo país tenham acesso a esse conteúdo tão relevante no cenário educacional brasileiro". A Figura 4 demonstra a disponibilização de materiais organizados de forma cronológica aos estudantes.

Figura 4: Detalhe dos recursos oferecidos nos cursos.

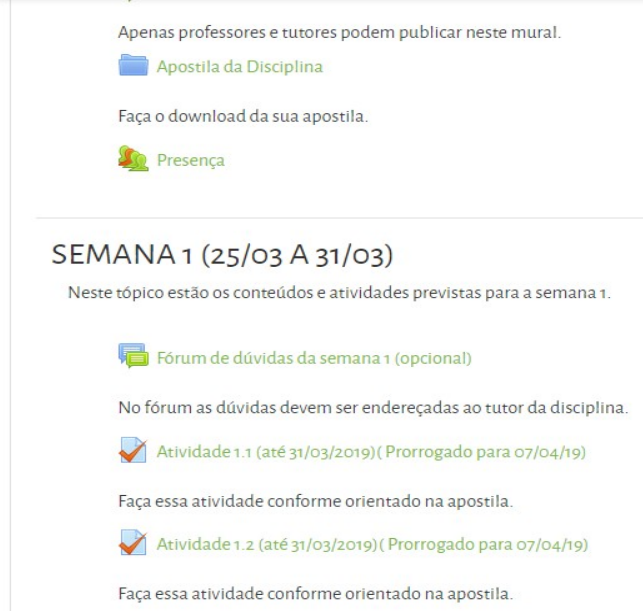

Fonte: IFMG.

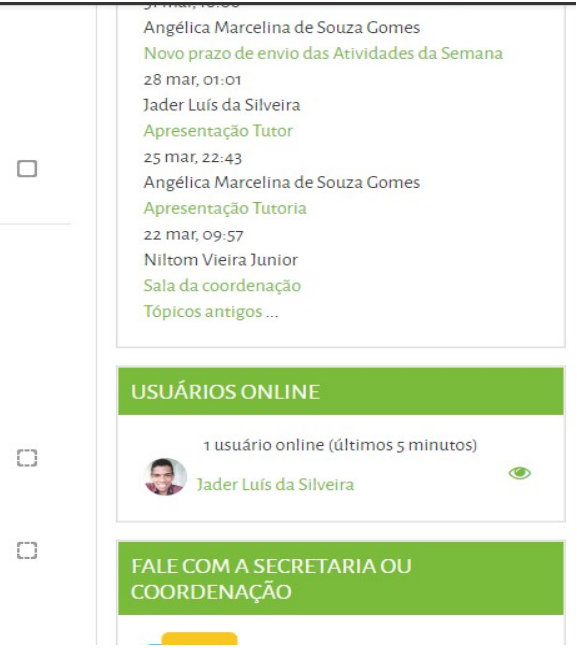

Uma iniciativa bastante interessante no curso de especialização em Docência e no curso FIC em Tecnologias na Educação é a criação de um laboratório virtual, onde os alunos têm a possibilidade de conhecer e manusear todos os recursos e plugins do Moodle, proporcionando, assim, uma excelente oportunidade de capacitação de uso 
desse AVA para os cursistas interessados em trabalhar no ensino a distância.

\section{Discussão do tema e resultados}

Baseado no estudo descritivo sobre o $\mathrm{EaD}$ no Instituto Federal de Minas Gerais Campus Avançado Arcos, constatou-se que a modalidade possui sinergia com o Plano de Desenvolvimento Institucional, como ferramenta de disseminação do ensino técnico e superior em seus 17 campi. E, para isso, a Diretoria de Desenvolvimento Institucional conta com quatro departamentos de apoio (supracitados na seção Descrição do caso) e um constante progresso em Tecnologia de Informação e Comunicação (TICs).

O Campus, por meio do CEAD, tem forte contribuição social, e o EaD vem sendo uma alternativa, por parte de políticas públicas de governos, para promover a inclusão social e digital. Além disso, é utilizado como instrumento de fundamental importância para atender a grandes contingentes de alunos de modo mais barato e flexível quando comparado ao ensino presencial.

É com esse viés que o AVA Moodle transformou-se de um repositório de dados das disciplinas em um centro estratégico de ensino-aprendizagem com um aumento da capacidade discente em oito vezes em relação à capacidade discente no passado (que era exclusivamente presencial).

Apesar da necessidade de ajustes e aperfeiçoamentos no Moodle utilizado pela instituição, dentre seus diversos recursos, pode-se citar a utilização de fóruns, multimídia, materiais de apoio e questionários. Além de, conforme Figura 5, ser um ambiente unificado de estratégias de ensino e de salas virtuais.

Figura 5: Lista de cursos instalados no Moodle.

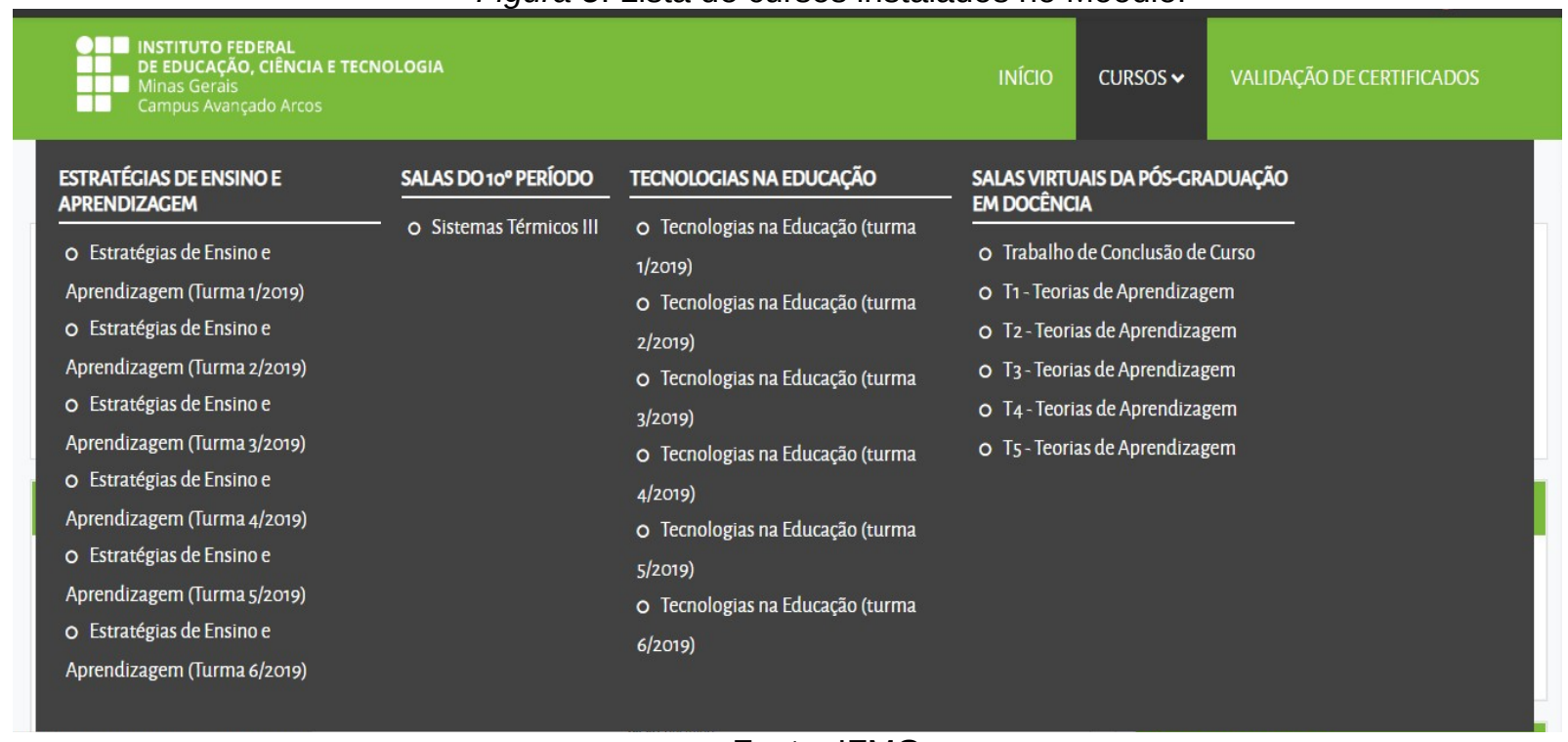

Fonte: IFMG.

O IFMG Campus Arcos busca produzir em seu estúdio do CEAD, vídeos personalizados, institucionais, materiais didáticos e softwares para cursos a distância e 
presencial. O uso das tecnologias da informação e comunicação também auxilia outros campi a produzir seus materiais didáticos e servir como uma possível base para implantação de cursos stricto sensu através do ensino a distância. Por meio dessas iniciativas, discentes e docentes participam, efetivamente, do processo de produção e divulgação de softwares e do próprio AVA Moodle. Neste contexto, tendo em vista o objetivo do artigo, que é analisar o impacto das TICs aplicadas no ensino Ead do Instituto Federal de Minas Gerais - Campus Avançado Arcos, foi possível constatar que o uso das TICs favorece os propósitos do EaD, tais como massificação do aprendizado, aumento do acesso e direito constitucional à educação pública de qualidade e inclusão social, além de integrar discentes e docentes no processo de geração do conhecimento.

\section{Considerações finais}

Diante da nova realidade do ensino a distância, o aumento da utilização e desenvolvimento das TICs, foi analisado, no presente estudo, seu impacto no ensino superior brasileiro. Assim, foi feito um estudo descritivo no Instituto Federal de Minas Gerais, no Campus Avançado Arcos, onde são utilizados o AVA Moodle e as TICs são desenvolvidas para esta interface de ensino e aprendizagem.

Constata-se que as políticas públicas e de ensino são espelhadas de acordo com a modalidade de ensino na qual é desempenhada, tais como os resultados obtidos pela massificação do aprendizado, aumento do acesso e direito constitucional à educação pública de qualidade e inclusão social. Portanto, principalmente pela sua função pública de garantia da democracia e difusão da educação, o Instituto Federal teve o EaD e o uso e desenvolvimento contínuo de suas TICs, um prolongamento de suas atribuições. Sendo ambos vitais para manutenção dos seus propósitos enquanto instituição e função políticosocial.

\section{Referências}

ALMEIDA, M. E. B. de. Educação a distância na internet: abordagens e contribuições dos ambientes digitais de aprendizagem. Educação e pesquisa, v. 29, n. 2, p. 327-340, 2003.

ALMEIDA, M. E. B. Educação a distância no Brasil: diretrizes políticas, fundamentos e práticas. In: 6 Congreso Iberoamericano, 4 Simposio Internacional de Informática Educativa, 7 Taller Internacional de Software Educativo [Archivo de ordenador]: IE-2002: Vigo, 20, 21, 22 de Noviembre de 2002. Servizo de Publicacións, 2002. p. 102.

ALONSO, K. M. A expansão do ensino superior no Brasil e a EaD: dinâmicas e lugares. Educação \& Sociedade, v. 31, n. 113, p. 1319-1335, 2010.

ALVES, L. Educação a distância: conceitos e história no Brasil e no mundo. Revista Brasileira de Aprendizagem Aberta e a Distância, v. 10, p. 83-94, 2011.

BARBOSA, C. M. A. M. A aprendizagem mediada por TICs: interação mediada por TICs e 
cognição em perspectiva. Faculdade de Ensino Superior Dom Bosco. RBAAD Associação Brasileira de Educação a Distância, v. 11, p. 84-100, 2012.

BORBA, M. C.; ASKAR, P.; ENGELBRECHT, J.; GADANIDIS, G.; LLINARES, S.; AGUILAR, M. S. Blended learning, e-learning and mobile learning in mathemaTICss education. ZDM, v. 48, n. 5, p. 589-610, 2016.

BRASIL. Decreto n. 2.494, de 10 de fevereiro de 1998. Regulamenta o art. 80 da Lei n. 9.394, de 20 de dezembro de 1996, e dá outras providências. Diário Oficial da União, Brasília, DF, 11 fev. 1998.

CASTELLS, M. A galáxia da internet: reflexões sobre a internet, os negócios e a sociedade. Rio de Janeiro: Jorge Zahar Ed., 2000.

CASTRO, C. M. Os dinossauros e as gazelas do ensino superior. In: MEYER JR, V. (Org.). Dinossauros, gazelas e tigres: novas abordagens da administração universitária - um diálogo Brasil e EUA. Florianópolis: Insular, 2000. p. 23-38.

CIDRAL, W. A.; OLIVEIRA, T.; DI FELICE, M.; APARICIO, M. E-learning success determinants: Brazilian empirical study. Computers \& Education, v. 122, p. 273-290, 2018.

FARIAS, S. C. Os benefícios das tecnologias de informação e comunicação (TICs) no processo de educação a distância (EAD). RDBCl: Revista Digital de Biblioteconomia e Ciência da Informação, v. 11, n. 3, p. 15-29, 2013.

FÓRUM NACIONAL DE PRÓ-REITORES DE GRADUAÇÃO DAS UNIVERSIDADES BRASILEIRAS - ForGRAD. Educação a Distância (EAD) na graduação: as políticas e as práticas. Curitiba, 2002.

GOMES, S. G. S. Tópicos em EAD. Rio de Janeiro: Fundação CECIERJ, 2009.

GOMES, S. G. S. Tópicos em educação a distância. 2016.

INSTITUTO FEDERAL DE MINAS GERAIS - IFMG. Institucional. Centro de Educação Aberta e a Distância. Disponível em: https://www.ifmg.edu.br/ceadop3/acesso-ainformacao/institucional. Acesso em: 02 dez. 2019.

INSTITUTO FEDERAL DE MINAS GERAIS - IFMG. Plano de Desenvolvimento Institucional (PDI) do Instituto Federal de Educação, Ciência e Tecnologia de Minas Gerais (IFMG) - 2014 a 2018. Instituto Federal de Educação, Ciência e Tecnologia de Minas Gerais. Resolução IFMG 019 de 09 de julho de 2014. Disponível em: https://www.ifmg.edu.br/ouropreto/institucional/plano-de-desenvolvimento-

institucional/resolucao0192014anexopdi20142018_versaofinal_revisado_02_07_2014.pdf. Acesso em: 02 dez. 2019.

INSTITUTO FEDERAL DE MINAS GERAIS - IFMG. Projeto Pedagógico do Curso de PósGraduação Lato Sensu em Docência na Educação Básica ou Profissional. Instituto Federal de Educação, Ciência e Tecnologia de Minas Gerais. 2019. Disponível em: 
https://www.ifmg.edu.br/arcos/documentos-do-site/ppc_ebp_03-12.pdf. Acesso em: 02 dez. 2019.

INSTITUTO FEDERAL DE MINAS GERAIS - IFMG. Resultados do curso a distância "Estratégias de Ensino e Aprendizagem". Instituto Federal de Educação, Ciência e Tecnologia de Minas Gerais. 2018. Disponível em: https://www.ifmg.edu.br/arcos/noTICsias/primeiros-resultados-do-curso-a-distanciaestrategias-de-ensino-e-aprendizagem. Acesso em: 02 dez, 2019.

KENSKI, V. M. Educação e tecnologias: O novo ritmo da informação. Campinas, SP: Papirus, 2007.

LÉVY, P. As tecnologias da inteligência: o futuro do pensamento da era da informática. 34. ed. 1998.

LOBO NETO, F. Educação a Distância sem distanciamento da educação. Tecnologia Educacional, Rio de Janeiro, v. 22, n. 123/124, p. 13-16, mar/jun., 1995.

MARTíNEZ, D. É. G.; BIZELLI, J. L.; INFORSATO, E. C. Tecnologias de informação e comunicação no ensino superior: o ambiente virtual de aprendizagem em curso semipresencial. Revista Ibero-Americana de Estudos em Educação, v. 12, n. 2, p. 14211440, 2017.

MATTAR, J. Guia de educação a distância. São Paulo: Cengage Learning, Portal Educação, 2011.

MENDONÇA, J. R. C.; PAIVA, K. C. M.; PADILHA, M.; BARBOSA, M. A. C.; MARTINS, M. A. B. Competências Eletrônicas de Professores para Educação à distância no Ensino Superior no Brasil: discussão e proposição de modelo de análise. In: II Conferência do FORGES - Fórum da Gestão do Ensino Superior nos países e regiões de língua portuguesa. Macau, China: Por um Ensino Superior de Qualidade nos Países e Regiões de Língua Portuguesa. 2012. p. 1-15.

MINISTÉRIO DA EDUCAÇÃO E CULTURA - MEC. TICs na EaD brasileira. 2018. Disponível em: $\quad$ http://portal.inep.gov.br/busca? 3 keywords= \%20TICs+na+Universidade+Brasileira+a+Dist \%C3\%A2ncia\&amp; 3 formDate $=1441824476958 \& a m p ; p \_p$ id =3\&amp; $p \_p$ lifecycle=0\&a mp;p_p_state $=$ normal\&amp; $p \_p$ mode $=v i e w \& a m p ; p \_p$ col id $=$ colun$\mathrm{p} \_\mathrm{p}$ _col_count=1\&amp; 3 struts_action=. Acesso em: 28 nov. 2019.

MORENO, V.; CAVAZOTTE, F.; ALVES, I. Explaining university students' effective use of elearning platforms. British Journal of Educational Technology, v. 48, n. 4, p. 995-1009, 2017.

PEREIRA, C. A.; WEN, C. L.; TAVARES, H. Alcohol abuse management in primary care: an e-learning course. Telemedicine and e-Health, v. 21, n. 3, p. 200-206, 2015.

PIMENTEL, N. M. Educação a distância. Florianópolis: Secretaria de educação a distância (SEAD/UFSC), 2006. 
RODRIGUES, M. W.; ISOTANI, S.; ZÁRATE, L. E. Educational Data Mining: A review of evaluation process in the e-learning. Telematics and InformaTICss, v. 35, n. 6, p. 17011717, 2018.

SARAIVA, T. Educação a distância no Brasil: lições da história. Em aberto, v. 16, n. 70, 2008.

Recebido em dia 04 de fevereiro de 2020.

Aprovado em dia 04 de maio de 2020. 